\title{
College Students' Attitude towards the Internet as Communication Medium and Level of Utilization of English Language in the Classroom
}

\author{
Antonio R. Yango', Pedrito Jose V. Bermudo', Erwin B. Quendangan² \\ ${ }^{1}$ University of Perpetual Help System Laguna, Biñan, Philippines \\ ${ }^{2}$ AMA University, Quezon City, Philippines \\ Email: jan.yango1964@gmail.com, pete_bermudo@yahoo.com, ebquendangan@amaes.edu.ph
}

How to cite this paper: Yango, A.R., Bermudo, P.J.V. and Quendangan, E.B. (2019) College Students' Attitude towards the Internet as Communication Medium and Level of Utilization of English Language in the Classroom. Open Journal of Social Sciences, 7, 438-452.

https://doi.org/10.4236/jss.2019.77036

Received: February 7, 2019

Accepted: July 28, 2019

Published: July 31, 2019

Copyright $\odot 2019$ by author(s) and Scientific Research Publishing Inc. This work is licensed under the Creative Commons Attribution International License (CC BY 4.0).

http://creativecommons.org/licenses/by/4.0/

(c) (i) Open Access

\begin{abstract}
This descriptive-correlational study attempted to determine how college students' attitude towards the internet as communication medium influences their level of utilization of the English language in the classroom at the University of Perpetual Help System Laguna-Philippines during the second semester of AY 2017-2018. The respondents were the fifty (50) college students who took Technical Writing and Philippine Literature courses during the aforesaid term. The researcher employed simple random sampling technique in selecting the respondents. The findings revealed that there was no significant relationship between the students' attitude towards the Internet as communication medium and level of utilization of the English language in the classroom considering the obtained $\mathrm{p}$ value of 0.211 which was greater than the significance level@0.05. This comprehensive study concludes that although there are many pluses, students have diverse estimations and attitudes towards this contemporary process of learning using the internet as communication medium. Likewise, teachers play a very bulging part in enticing the student's attention to maximize the use of English language in the classroom which can be possibly acquired by creating interest among them through the employment of media platforms particularly the Internet which nowadays is undeniably inseparable from teaching and learning of the English language.
\end{abstract}

\section{Keywords}

College Students, Attitude, College Students' Attitude, Internet as

Communication Medium, Utilization, English Language, Classroom 


\section{Introduction}

The mass media branch out media technologies that are intended to reach a large audience by mass communication. The technology through which this communication takes place diverges. Broadcast media such as radio, recorded music, film and television convey their information electronically. Print media use a physical object such as a newspaper, book, pamphlet or comics, to distribute their information. Outdoor media are a form of mass media that consist of billboards, signs, or placards placed inside and outside of commercial buildings, sports stadiums, shops, and buses.

The use of social media has changed people's communicative patterns over the last 10 years by enabling users "to create, distribute, share and manipulate different types of content, most of them publicly accessible". The first social media application was MySpace in 2003, followed by the now big players Facebook 2004, YouTube 2005 and Twitter 2006. The advent of social media has also instigated the move from web 1.0 to web 2.0, which is an evolution from the linking of information (web 1.0) to the linking of people (web 2.0) [1]. This means that the introduction of new technologies and people being more easily linked on a more global scale has impacted new communicative practices.

In the study made by Draskovic [2] in Student attitudes towards use of Social media in the learning process-social media and social networks changed the way people communicate and interact with their friends and peers. They also changed the way people consume media content. Social media gave the users an opportunity to become contributors and creators of digital content. Just a decade ago, during the emerging phase, social media platforms were considered a novelty and their commercial value was still questionable, at least outside the IT industry. However, a growing user base and saturation of traditional mass media resulted in further commercial exploitation of social media platforms. In 2015, eMarketer showed that social network ad spending reached $\$ 23.68$ billion worldwide. Marketers are shifting their budget from declining traditional media, such as print and TV, toward more dynamic and interactive digital media, such as social media and mobile platforms.

Ellefsen et al. [3] implied that social media also became relevant in academia. With widespread adoption among students, social media has huge potential as a communication and education tool. In overall, educators are aware of social media's benefits and high adoption rates. However, there are also some reservations and challenges preventing full adoption of social media for lecturer-student engagement, such as differing opinions about social media's role in the higher education environment and the rather informal nature of social media.

The study Eyo [4] showed that the advent of the computer and indeed the application of Information and Communications Technology (ICT) in human relations have changed the face of social interaction. This forward progression has also emphasized the need to be up-to-speed with this trend. The majority of teachers say that they make regular use of ICT in their teaching and an increas- 
ing number of countries include ICT in the curriculums of initial teacher training programs. Inclusion of ICT tools within the educational process is particularly effective in increasing efficiency and productivity as well as in diversifying the professional activities of teachers. Examples of such tools are lessons preparation and authoring tools, test service systems, student tracking tools, portfolio systems and complete educational packages/learning management systems (e.g.

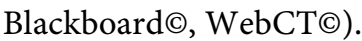

Gonen, Sharon, \& Lev-Ari [5] specified that the Internet has been regarded as one of the most influential and transformative technologies for teaching and learning among all ICT tools. Internet has the capacity to improve interactive communication processes among people, institutions and organizations at different levels. It can also help in the collection of information about social, economic and political issues.

Over the past decade, many studies have been conducted to investigate students' attitudes towards the Internet. Few of these studies are from Chou in 2016-these studies, in general, revealed that students have favorable attitudes concerning the Internet. In these studies also, Ünlü and Sue [6] they stated that physical education teachers and physical education teacher candidates were efficient in their usage of the Internet. Another study indicated that prospective physical education (PE) teachers have high computer self-efficacy.

In the Physical Education field, educational applications related to the computer and the Internet have become more wide-spread allowing teachers to present visual aids more easily and hold more interactive classes [7]. Previous studies also specified that a great majority of students use the Internet on a daily basis and use the Internet for social networking, educational and recreational purposes Widespread use of the Internet has come about not only in the field of education, but also in many other contexts.

Borge and Cardenal [8] indicated that the Internet is seen as a tool to develop and protect democracy in the world. The Internet provides individuals with the ability to communicate and share their opinions directly with others by ignoring socioeconomic, gender, religious, ethnic and national differences. This improves democratic participation and has led to the creation of a digital community. On the other hand, Gainous, Wagner, and Gray [9] detailed that freedom of the Internet provides more positive attitudes towards democracy. It can be stated that the Internet will make important contributions to the rebirth of democracy.

Bryan [10] expressed that the growth rate of the Internet specifically social media networks has extensively become popular among young adults. The term social media/social network has different connotations in the literature. Some researchers defined it as "socially interactive technologies"; for example; instant messaging or text messaging, or other networks which offer fast-paced inexpensive online communication which allows social interaction to start and evolve. Researchers have been discussing on the nature and quality of activities conducted on social media. A study conducted by Chang and Cheng [11], found that there are significant differences between online and offline relationships. 
Online relationships are characterized as less depth however it provides extra connections to the existing participants of social networks. This means more relationships exists but less of the strong ones. Sheldon et al. [12] found that social media is commonly used by people who are not willing to have face-to-face interactions. The research on Impact of Social Media among youngster (students') attitude requires researcher to employ network thinking to understand young people social experiences and how it influences their behavior as it provides ways to investigate and interpret the links among social networks and how it affects their attitude.

Cabigon [13] stated that the Philippines is recognized globally as one of the largest English-speaking nations with majority of its population having at least some degree of fluency in the language. English has always been one of the official languages of the Philippines and is spoken by more than 14 million Filipinos. It is the language of commerce and law, as well as the primary medium of instruction in education. Proficiency in the language is also one of the country's strengths that has helped drive the economy and even made the Philippines the top voice outsourcing destination in the world, surpassing India in 2012. The influx of foreign learners of English is also on the rise due to the relatively more affordable but quality English as a Second Language (ESL) programs being offered locally.

Lhurda [14] stated that the English language is one of the most widely spoken languages in the world besides French, German and other languages. It is an important language because of its international status, having gained over time, the status of a world language. With this status, it has also become a medium of inter-cultural communication of all the Commonwealth countries globally.

Juma [15] shows that teachers of the English language are trained to employ all possible teaching strategies to teach their students. They have at their discretion, the capability to employ appropriate teaching methods and resources along the content they give to their students. The teachers have informed choices, to select from numerous types of resources, equipment and materials for English language learning and teaching. These equipment and materials however, unless used effectively by trained and qualified personnel, as expected, may not necessarily enhance student learning in the English language. Students therefore require maximum opportunity to understand what they are being taught, which is only possible if the content given in training is clearly understood within the available context with proper utilization of the existing resources.

Effective delivery of content by use of every appropriate strategy and resource is of great concern and is worth laying emphasis on as stated by Dick and Carey [16]. This study confirmed that teaching without using instructional media to enhance learning may negatively affect students' learning.

Reasonable and practical involvement of learners should be allowed when their teachers' use of instructional media in lessons to aid in internalizing the taught language concepts, develop given speaking, listening, reading and study 
skills thereby boosting its performance. Students require concrete experiences to retain more knowledge and skills hence learn more effectively. The experiences involve the use of instructional media to facilitate learning and acquisition, retention and application of abstract symbols. Over time in their studies, scholars have discussed the effectiveness of visual aids as being more than those of the lecture methods globally. The visual aids like charts and video enhance the amount of content the pupils remember, the enhanced understanding of concepts presented, and the enjoyment experienced when the visual aids are utilized. The role of these materials in teaching and learning has neither changed nor ceased. Where these vital resources are not used to the optimum, students' learning may be compromised.

On the other hand, this study confirmed that substantial access to resources contributes to the teachers' and learners' competence in utilizing them, which remains an exception, given challenges related to access and availability to both students and teachers in schools. Thus, availability and effective use of the resources for teaching and learning the English language meant pairing the resources with an instructional approach. This was very different from the traditional one where more information was therefore needed on the nature and extent of teachers' experience in use of these technologies. Hence, how teachers viewed these resources, how they understood their impact in use and how they altered their instructional practices in order to use them effectively was a concern for this study. This study established whether and how often the materials were used by teachers in enhancing learning of the English language and the use of the teaching aids by teachers of the English language [17].

Research in the use of ICT to enhance teaching and learning abounds in literature. Though some scholars believe that these studies are inconclusive, nonetheless, they point to the fact that ICT in education can make both positive and negative impact on students' learning. On the positive side, Hennessey et al. [18] found that when appropriately utilized, "technology increased learners' motivation, engagement and participation through providing novelty and variety, creating interest and excitement and adding more fun in the classroom".

In addition, Purcell et al. [19] indicated that ICT tools "encourage student creativity and personal expression; encourage greater collaboration among students; and allow them to share their work with a wider and more varied audience". Studies carried out at University of Botswana (UB) revealed that the use of technology in teaching and learning has a positive impact. According to Borge and Cadernal [8], students reported that "using technology in learning ... greatly improved their understanding of course content; the use of WebCT and other online courses made course materials easily accessible, reduced elaborate and extensive note-taking in class and helped them participate in online discussions with their lecturers and classmates". Also, Oladinan and Uziak [20] revealed that “technology generated interest in students' courses, enhanced learning and understanding of course materials, provided useful feedback on assignments and 
improved interaction between learners and their lecturers". However, these studies did not focus on first year undergraduates of the university. Despite the positive impact reported in these studies, the use of technology in teaching and learning has its problems and challenges. For example, technology has been said to encourage student laziness since at the junior secondary school level, computer awareness course is introduced and most of the junior schools have a computer laboratory. However, the computer as an ICT tool has not yet been integrated into the school lessons nor is it part of the examinable subjects in the Junior Certificate examinations. At the senior secondary school level, Computer Studies as a subject is part of the school curriculum and it is an examinable subject which is offered as an optional course. However, because of the mindset of students who normally associate computing with such difficult subjects as Math and Science, most students do not opt for Computer Studies at the senior secondary school level.

From the viewpoints presented by the authorities in the fields considering the variables under study, the researcher attempted to determine how college students' attitude towards the internet as communication medium influence their level of utilization of the English language in the classroom at the University of Perpetual Help System Laguna during the Summer term of 2018.

\section{Methods}

This study was conducted at the University of Perpetual Help System Laguna, City of Biñan Laguna, Philippines. The study made use of the descriptive-correlation design and it employ simple random sampling technique in selecting the respondents. It included fifty (50) students which was 10 percent of the 500 students who took Technical Writing and Philippine Literature courses during second semester of academic year 2017-2018 at the University of Perpetual Help System Laguna, Philippines. The study utilized a survey using a questionnaire to determine how the college students' attitude towards the internet as communication medium influences their level of utilization of English language in the classroom. To come up with the best results and to solicit thorough and ideal responses from the respondents, the researcher made a self-made questionnaire consisting of two (2) parts, the first part contained statements which focused on determining the respondents' attitude towards the internet as communication medium and the second part dwelled on statements which measured the respondents' level of utilization of English language in the classroom. Since the research instruments used in the study was non-standardized, they were presented to the panel of experts in the field of English language teaching, in research and in statistics for their comments and comprehensive suggestions. Likewise, to strengthen the validity and reliability of the constructed survey questionnaire, it underwent reliability test with an obtained Cronbach Alpha of 0.893 for students' attitude towards the Internet as communication medium and 0.870 for students' level of utilization of the English language in the classroom. 
Before the actual data gathering started, the researcher made a letter seeking permission to conduct the investigation from the deans of the College of Arts and Sciences and College of Education of the afore-mentioned University. Final administration of the questionnaire was done upon the approval of the aforesaid request. The researcher personally did the administration and retrieval of the questionnaires with the assistance of his colleagues in the two departments mentioned who voluntarily extended their help for the success of the study. After which, the data were collected and tabulated for statistical analysis with the guidance of his statistician and consultant.

To give direction to the study, the hypothesis which was in the null form and stated that there was no significant relationship between the college students' attitude towards the internet as communication medium and their level of utilization of the English language in the classroom was subjected to statistical testing. To arrive at scholarly findings, appropriate statistical tools were used, such as weighted mean to determine the central tendency of respondents' responses to the questions posed; arithmetic mean to find the sum of all weighted means and the number of items/criteria, and standard deviation to know the sum of the square of the relationship between the weighted mean and arithmetic mean and Pearson $r$ for the relationship problem.

\section{Results and Discussion}

Table 1 presents the students' profile, out of fifty (50) students, to age, as twenty-nine (29) or 58 percent were under the age bracket of 19 and above while twenty one (21) or 42 percent aged 17 - 18. As to gender, twenty- six (26) or 52 percent were male while twenty-four (24) 48 percent were female. In terms of degree program, fifteen (15) or 30 percent were in Maritime Education, twelve (12) or 24 percent were in HRM/TM, eleven (11) or 22 percent were in Education, seven (7) or 14 percent were in Business, three (3) or 6 percent were in Arts and Sciences and two (2) or 4 percent were in Engineering. The results showed that almost one third (1/3) of the student respondents were in Maritime Education.

Table 2 presents the students' attitude towards the internet as communication medium, as shown, indicator which states that "I see internet as a valuable mode of communication" got a weighted mean of 3.38 and was ranked 1, indicators 2 and 6 which state that "I feel I can communicate better in the internet" and "I think that the internet has done its purpose of connecting people from one point of the globe to the next" both had a weighted mean of 3.32 and were ranked 2.5 respectively, and indicator 8 which states that "I believe that the internet as a medium of communication helps people to socialize and to make friends online" got a weighted mean of 3.26 .

On the other hand, indicator 15 which states that "I feel that the internet has provided the fastest way of sending and receiving information" had a weighted mean of 2.84 and was ranked 15, indicator 13 which states that "I believe that the 
internet gives me the opportunity to process the received message before replying" got a weighted 2.96 and was ranked 14, and indicators 12 and 14 which state that" I believe that the internet enhances the process of communication with two or more speakers" and "I believe that the internet is the most convenient way of communication" both had a weighted mean of 3.02 and were ranked 12.5 respectively. All the indicators were interpreted as positive. To sum up an average weighted mean of 3.15 revealed that the students had positive attitude towards the internet as communication medium.

The findings support the study made by Ellefsen et al. [3] who posited that social media also became relevant in academia. With widespread adoption among students, social media has huge potential as a communication and education tool. In overall, educators are aware of social media's benefits and high adoption rates. However, there are also some reservations and challenges preventing full adoption of social media for lecturer-student engagement, such as differing opinions about social media's role in the higher education environment and the rather informal nature of social media.

Table 3 presents the students' level of utilization of English language in the classroom, as shown, indicator 15 which states that "I apply language standards (grammar) when speaking in English" had a weighted mean of 3.10 and was ranked 1, indicator 14 which states that "I apply correct pronunciation when speaking in English" got a weighted mean of 3.08 and was ranked 2, and indicators 4 and 13 which state that "I use the English language when I am in the academic setting" and "I use the English language when I search for certain information online" both had a weighted mean of 3.06 and were ranked 3.5 respectively.

Table 1. The students' profile.

\begin{tabular}{|c|c|c|c|}
\hline \multicolumn{2}{|c|}{ Profile } & \multirow{2}{*}{$\begin{array}{c}\text { Frequency } \\
21\end{array}$} & \multirow{2}{*}{$\begin{array}{c}\text { Percentage } \\
42.00\end{array}$} \\
\hline Age & $17-18$ & & \\
\hline & 19 and above & 29 & 58.00 \\
\hline \multirow[t]{2}{*}{ Gender } & Male & 26 & 52.00 \\
\hline & Female & 24 & 48.00 \\
\hline \multirow[t]{6}{*}{ Degree Program } & Maritime & 15 & 30.00 \\
\hline & Engineering & 2 & 4.00 \\
\hline & $\mathrm{HRM} / \mathrm{TM}$ & 12 & 24.00 \\
\hline & Education & 11 & 22.00 \\
\hline & Business & 7 & 14.00 \\
\hline & Arts \& Sciences & 3 & 6.00 \\
\hline \multirow[t]{3}{*}{ Year level } & $2^{\text {nd }}$ year & 3 & 6.00 \\
\hline & $3^{\text {rd }}$ year & 42 & 84.00 \\
\hline & $4^{\text {th }}$ year & 5 & 10.00 \\
\hline
\end{tabular}

Total Number of Respondents $=50$. 
Table 2. The students' attitude towards the internet as communication medium.

\begin{tabular}{|c|c|c|c|}
\hline Indicators & $\begin{array}{l}\text { Weighted } \\
\text { Mean }\end{array}$ & $\begin{array}{l}\text { Verbal } \\
\text { Interpretation }\end{array}$ & Rank \\
\hline 1) I see internet as a valuable mode of communication. & 3.38 & Positive & 1 \\
\hline 2) I feel I can communicate better in the internet. & 3.32 & Positive & 2.5 \\
\hline $\begin{array}{l}\text { 3) I believe that the internet helps people to contact each } \\
\text { other easily. }\end{array}$ & 3.22 & Positive & 6.5 \\
\hline $\begin{array}{l}\text { 4) I think that the internet helps people to express themselves } \\
\text { freely. }\end{array}$ & 3.22 & Positive & 6.5 \\
\hline $\begin{array}{l}\text { 5) I feel that the internet is an innovative form of social media } \\
\text { platform. }\end{array}$ & 3.20 & Positive & 8 \\
\hline $\begin{array}{l}\text { 6) I think that the internet has done its purpose of connecting } \\
\text { people from one point of the globe to the next. }\end{array}$ & 3.32 & Positive & 2.5 \\
\hline $\begin{array}{l}\text { 7) I find myself comfortable when communicating through } \\
\text { the internet. }\end{array}$ & 3.24 & Positive & 5 \\
\hline $\begin{array}{l}\text { 8) I believe that the internet as a medium of communication } \\
\text { helps people to socialize and to make friends online. }\end{array}$ & 3.26 & Positive & 4 \\
\hline 9) I feel at ease when communicating through the internet. & 3.12 & Positive & 9 \\
\hline 10) I like communicating through the internet. & 3.06 & Positive & 11 \\
\hline 11) I get excited when I communicate using the internet. & 3.08 & Positive & 10 \\
\hline $\begin{array}{l}\text { 12) I believe that the internet enhances the process of } \\
\text { communication with two or more speakers. }\end{array}$ & 3.02 & Positive & 12.5 \\
\hline $\begin{array}{l}\text { 13) I believe that the internet gives me the opportunity to } \\
\text { process the received message before replying. }\end{array}$ & 2.96 & Positive & 14 \\
\hline $\begin{array}{l}\text { 14) I believe that the internet is the most convenient way of } \\
\text { communication. }\end{array}$ & 3.02 & Positive & 12.5 \\
\hline $\begin{array}{l}\text { 15) I feel that the internet has provided the fastest way of } \\
\text { sending and receiving information. }\end{array}$ & 2.84 & Positive & 15 \\
\hline Average & 3.15 & Positive & \\
\hline
\end{tabular}

Table 3. The students' level of utilization of the English language in the classroom.

\begin{tabular}{|c|c|c|c|}
\hline Indicators & $\begin{array}{l}\text { Weighted } \\
\text { Mean }\end{array}$ & $\begin{array}{l}\text { Verbal } \\
\text { Interpretation }\end{array}$ & Rank \\
\hline 1) I try to use the English language as much as possible. & 2.76 & High & 13 \\
\hline 2) I speak in English when I talk with my peers. & 2.64 & High & 14 \\
\hline 3) I use the English language when I speak with my teachers. & 2.54 & High & 15 \\
\hline $\begin{array}{l}\text { 4) I use the English language when I am in the academic } \\
\text { setting. }\end{array}$ & 3.06 & High & 3.5 \\
\hline 5) I speak in English when engaged in formal conversations. & 2.94 & High & 10 \\
\hline 6) I use the English language during class presentations. & 2.94 & High & 10 \\
\hline 7) I speak in English when sharing my ideas. & 2.84 & High & 12 \\
\hline $\begin{array}{l}\text { 8) I use the English language when I communicate through } \\
\text { social media. }\end{array}$ & 3.02 & High & 6.5 \\
\hline 9) I use the English language when asking questions. & 2.94 & High & 10 \\
\hline
\end{tabular}




\section{Continued}

\begin{tabular}{|c|c|c|c|}
\hline $\begin{array}{l}\text { 10) I use the English language when asking for clarifications } \\
\text { during class discussion. }\end{array}$ & 3.00 & High & 8 \\
\hline 11) I use the English language during formal events. & 3.04 & High & 5 \\
\hline $\begin{array}{l}\text { 12) I use the English language when I speak with people of } \\
\text { authority. }\end{array}$ & 3.02 & High & 6.5 \\
\hline $\begin{array}{l}\text { 13) I use the English language when I search for certain } \\
\text { information online. }\end{array}$ & 3.06 & High & 3.5 \\
\hline 14) I apply correct pronunciation when speaking in English. & 3.08 & High & 2 \\
\hline $\begin{array}{l}\text { 15) I apply language standards (grammar) when speaking in } \\
\text { English. }\end{array}$ & 3.10 & High & 1 \\
\hline Average & 2.93 & High & \\
\hline
\end{tabular}

On the other hand, indicator 3 which states that "I use the English language when I speak with my teachers" had a weighted mean of 2.54 and was ranked 15, indicator 14 which states that "I speak in English when I talk with my peers" had a weighted mean of 2.64 and was ranked 14, indicator 1 which states that "I try to use the English language as much as possible" with 2.76 was ranked 13 and indicator 7 which states that "I speak in English when sharing my ideas" had a weighted mean of 2.84 and was ranked 12. All the indicators were interpreted as high. To sum up an average weighted mean of 2.93 revealed that the students had high level of utilization of English language in the classroom.

The findings support the study made by Cabigon [13] who stated that the Philippines is recognized globally as one of the largest English-speaking nations with majority of its population having at least some degree of fluency in the language. English has always been one of the official languages of the Philippines and is spoken by more than 14 million Filipinos. It is the language of commerce and law, as well as the primary medium of instruction in education. Proficiency in the language is also one of the country's strengths that has helped drive the economy and even made the Philippines the top voice outsourcing destination in the world, surpassing India in 2012. The influx of foreign learners of English is also on the rise due to the relatively more affordable but quality English as a Second Language (ESL) programs being offered locally.

Table 4 presents the difference in the students' attitude towards the internet as communication medium when grouped according to profile variables, as shown, the obtained $p$ values of 0.796 for age, 0.582 for gender. 0.055 for degree program and 0.144 for year level were greater than the significance level @ 0.05, therefore, no significant difference was observed. The results implied that the students' attitude towards the internet as communication medium is the same regardless of their age, gender, and degree program and year level.

The results support the study made by Borge and Cadernal [8] who indicated that the Internet is seen as a tool to develop and protect democracy in the world. The Internet provides individuals with the ability to communicate and share their opinions directly with others by ignoring socioeconomic, gender, religious, 
ethnic and national differences. This improves democratic participation and has led to the creation of a digital community.

Table 5 presents the difference in the students' level of utilization of the English language in the classroom when grouped according to profile variables, as shown, the obtained $\mathrm{p}$ value 0.033 for degree program was lesser than the significance level @ 0.05, therefore, there was a significant difference observed. The results implied that the students' level of utilization of the English language in the classroom is not the same regardless of their degree program. However, the obtained $\mathrm{p}$ values of 0.135 for age, 0.476 for gender and 0.086 for year level were greater than the significance level @ 0.05, therefore, no significant difference was noted. The results implied that the students' level of utilization of the English language in the classroom is the same regardless of their age, gender, and year level.

The results support the study made by Gainous, Wagner, and Gray [9] detailing that freedom of internet provides more positive attitudes towards democracy. It can be stated that the internet will make important contributions to the rebirth of democracy.

Table 6 presents the relationship between the respondents' attitude towards the internet as communication medium and level of utilization of the English language in the classroom, as seen, the obtained $\mathrm{p}$ value of 0.211 was greater than the significance level @ 0.05, therefore, no significant relationship was noted. The results inferred that the students' attitude towards the internet as communication medium has no bearing on their level of utilization for the fact that we are now living in the cyber age where various social media platforms are readily available for application and exploration.

Table 4. Difference in the students' attitude towards the internet as communication medium when grouped according to profile variables.

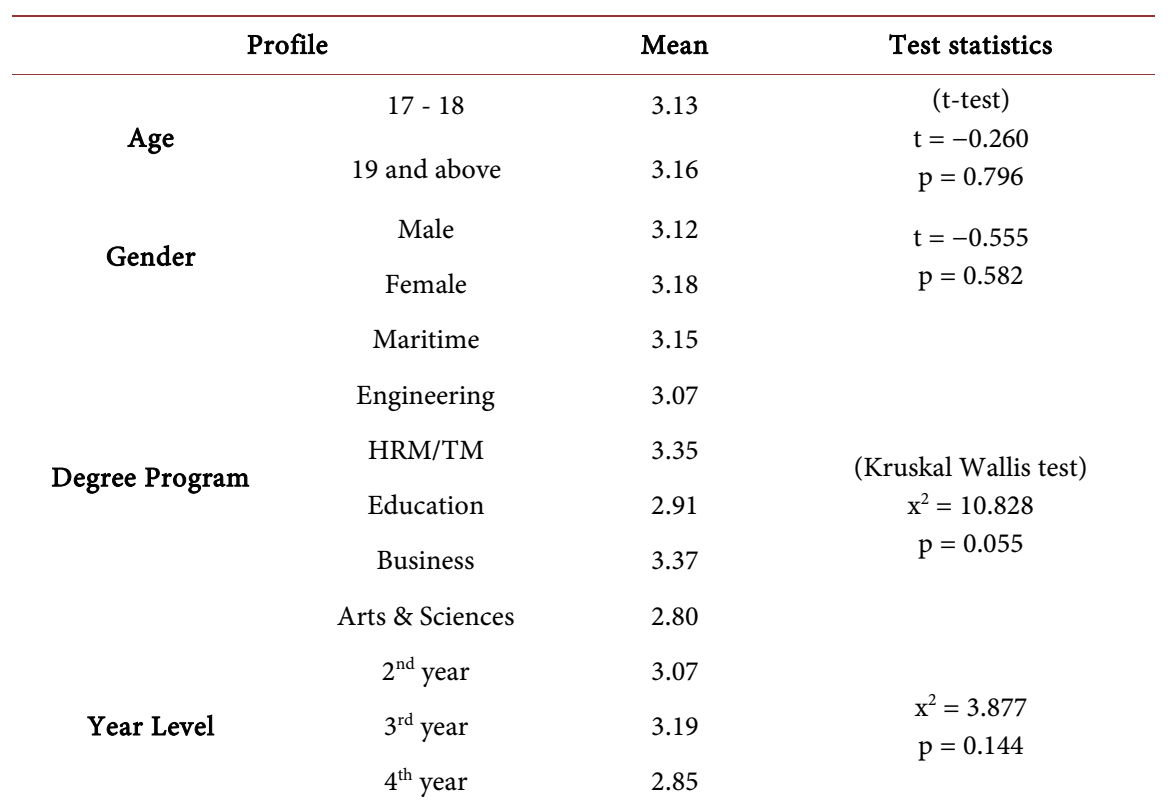

significance level@ 0.05 . 
Table 5. Difference in the students' level of utilization of the English language in the classroom when grouped according to profile variables.

\begin{tabular}{|c|c|c|c|}
\hline \multicolumn{2}{|c|}{ Profile } & Mean & Test statistics \\
\hline \multirow{2}{*}{ Age } & $17-18$ & 2.83 & $\begin{array}{c}\text { (t-test) } \\
\mathrm{t}=-1.520\end{array}$ \\
\hline & 19 and above & 3.01 & $\mathrm{p}=0.135$ \\
\hline \multirow{2}{*}{ Gender } & Male & 2.89 & $\mathrm{t}=-0.718$ \\
\hline & Female & 2.98 & $\mathrm{p}=0.476$ \\
\hline \multirow{6}{*}{ Degree Program } & Maritime & 2.85 & \\
\hline & Engineering & 2.34 & \\
\hline & $\mathrm{HRM} / \mathrm{TM}$ & 2.88 & (Kruskal Wallis test) \\
\hline & Education & 2.99 & $\begin{aligned} x^{2} & =12.151 \\
p & =0.033^{*}\end{aligned}$ \\
\hline & Business & 3.32 & (Between Engineering \& Business) \\
\hline & Arts \& Sciences & 2.78 & \\
\hline \multirow{3}{*}{ Year level } & $2^{\text {nd }}$ year & 2.62 & \\
\hline & $3^{\text {rd }}$ year & 2.98 & $\begin{aligned} x^{2} & =4.911 \\
p & =0.086\end{aligned}$ \\
\hline & $4^{\text {th }}$ year & 2.68 & \\
\hline
\end{tabular}

Significant @ 0.05 .

Table 6. Relationship between the respondents' attitude towards the internet as communication medium and level of utilization of the English language in the classroom.

\begin{tabular}{llll}
\hline Indicators & Pearson $\mathbf{r}$ & p-value & Interpretation \\
\hline $\begin{array}{l}\text { Students' Attitude towards the Internet as } \\
\begin{array}{l}\text { Communication Medium and Level of Utilization } \\
\text { of the English Language in the Classroom }\end{array}\end{array}$ & 0.180 & 0.211 & Not Significant \\
\hline
\end{tabular}

Significance level@ 0.05.

The results contradict the study made by Borge and Cardenal [1] which theorized that students reported that "using technology in learning ... greatly improved their understanding of course content; the use of WebCT and other online courses made course materials easily accessible, reduced elaborate and extensive note-taking in class and helped them participate in online discussions with their lecturers and classmates". Also, Oladinan \& Uziak [20] revealed that “technology generated interest in students' courses, enhanced learning and understanding of course materials, provided useful feedback on assignments and improved interaction between learners and their lecturers".

\section{Conclusion}

As Internet expedites communication no matter the distances, providing clear broadcast of various forms of information deemed necessary in the learning process, such as testing and valuation systems, e-learning becomes a more appropriate milieu for many students. The adeptness of starting such a program 
based on e-tools is under the effect of factors such as: students' attitudes, the helpfulness they perceive in using these riggings, the attitude towards adoption of technology and, of course, the technological background they have. To conclude, although, the student respondents had positive attitude towards the Internet as communication medium still they have diverse opinions and attitudes towards this contemporary process of learning using the internet as communication medium. Likewise, students' attitude towards the internet as communication medium has no bearing on their level of utilization based on the results of the study maybe due to the fact that we are now living in the cyber age where various social media platforms are readily available for application and exploration. From the comprehensive findings of the study, the faculty may realize the value of blended learning in the students' utilization of English language in the classroom; thus the students would become globally competitive when part of the professional and corporate world become.

\section{Limitations and Future Directions}

To intellectualize the very quintessence of the inquiry, the following recommendations are hereby endorsed: though the student respondents had positive attitude towards the Internet as communication medium and had high level of utilization of the English language in the classroom. It is recommended that they should align their potentials for significant and very positive use of the Internet for internet use nowadays it is indispensable in the teaching-learning process. Further, it is recommended that they can maximize the use of the internet in honing their craft or skills in the use of the English language in the classroom provided that such must be done within reasonable bounds.

Technology contributes to improving student achievement and performance in the use of the English language in the classroom in particular; it will also increase their participation and interaction with their teachers. The present study has its limitations. Given the small sample size of the study, it is recommended that further studies with larger samples be undertaken to develop more understanding of the research topic in general. Since this research was quantitative in nature, the findings cannot be generalized to the whole population. Hence, replication of the present study with a larger number of participants may provide more reliable findings. It is recommended that future research investigate learners' attitudes toward the use of other specific social media platforms in both private and public schools. Moreover, it is recommended that qualitative studies be done to find out the factors affecting attitudes of the English language learners toward Information Communication Technology (ICT) use in English language learning.

\section{Conflicts of Interest}

The authors declare no conflicts of interest regarding the publication of this paper. 


\section{References}

[1] Reinhardt, T. and Zander, F. (2011) Connectivism: Learning as Network-Creation. Learning Circuits. http://www.astd.org/LC/2005/1105_seimens.htm

[2] Draskovic, L. (2013) Gender, Religion, and New Media: Attitudes and Behaviours Related to the Internet Among Ultra-Orthodox Women Employed in Computerized Environments. International Journal of Communications, 5, 875-895.

[3] Ellefsen, M., Gates, T. and Calley, Q. (2016) Internet and Democracy: Is the Internet an Important Predictor for Physical Education Teacher Candidates' Attitudes towards Democracy?

[4] Eyo, V. (2016) Impact of Social Media on Intrapersonal Communication Patterns. University of Latvia, The University College of Economics and Culture, Institute of Philosophy and Sociology. Socialinių mokslų studijos, Riga, Latvia.

[5] Gonen, G., Sharon, M. and Lev-Ari, G. (2016) The Instructional Quality Profile: Curriculum Evaluation and Design Tool. In: Procedures for Instructional Systems Development, Academic Press, New York.

[6] Warschauer, M. (2014) Comparing Face-to-Face and Electronic Discussion in the Second Language Classroom. CALICO Journal, 13, 7-26.

[7] Okazaki, T., Mangim, K. and Sweller, J. (2014) Implications of the Cognitive Load Theory for Multimedia Learning. Cambridge University Press, New York.

[8] Özad, B.E. and Kutoğlu, Ü. (2010) The Use of the Internet in the Media Education. TOJET: The Turkish Online Journal of Educational Technology, 9, 245-255.

[9] Gainous, B., Wagre, T. and Gray, H. (2016) The Utilization of Technology to Improve English Speaking Skills. Journal for the Study of English Linguistics, 2, 19-24.

[10] Bryan, C. (2006) Using the Internet in Education-Strengths and Weaknesses. University of Gävle, Faculty of Education and Business Studies. University of Gävle, Gävle, Sweden.

[11] Chang, N. and Cheng, T. (2004) Student Attitudes toward the Use of Social Media in the Learning Process: A Comparative Study of Croatian and German Students. International Journal of Management Cases, 19, 52-64.

[12] Sheldon, D., Underhill, N. and Mayer, T. (2009) Testing Spoken Language: A Handbook of Oral Testing Techniques. Cambridge University Press, Cambridge.

[13] Cabigon, D. (2013) Students' Attitude towards the Uses of Interner. International Journal of Business and Management, 5, 46-55. http://www.ccsenet.org/ijbm

[14] Lhurda, R. (2004) Reading and Writing: The Connection to Personal, Social and Economic Development. International Journal of the School of Humanities and Social Sciences, 2, 106-119.

[15] Juma, H. (2008) Utilization of Language Services for Clients with Limited English Proficiency Protocols. United States of America: Committee Lep Diversity.

[16] Mahadi, S.R.S., Jamaludin, N.N., Johari, R., Firdaus, I.N. and Fuad, M. (2016) The Impact of Social Media among Undergraduate Students: Attitude. Procedia-Social and Behavioral Sciences, 219, 472-429. http://www.sciencedirect.com

[17] Farrant, N. (2010) English as a Foreign Language Students Attitudes towards the Utilization of iPad in Language Learning. MOJET-Malaysian Online Journal of Educational Technology, 5, 19-24.

[18] Hennesset, T. and Muindi, B. (2009) Cause of Poor Marks in English. Daily Nation.

[19] Roschelle, J. (2013) Unlocking the Learning Value of Wireless Mobile Devices. Journal of Computer Assisted Learning, 19, 260-272. 
[20] Oladinan, N. and Uziak, G. (2009) Effective Utilization of ICT in English Language Learning-The Case of University of Botswana Undergraduates. Universal Journal of Educational Research, 4, 1340-1350. https://doi.org/10.13189/ujer.2016.040611 